\title{
Impact of Norway spruce pre-degradation stages induced by $G$. trabeum on fungal and bacterial communities
}

\author{
Nicolas Valette, ${ }^{1,2}$ Arnaud Legout, ${ }^{2}$ Barry Goodell, ${ }^{3}$ Gry Alfredsen, ${ }^{4}$ Lucas Auer, ${ }^{1}$ Eric Gelhaye ${ }^{1}$
} and Delphine Derrien ${ }^{2}$

\author{
${ }^{1}$ Université de Lorraine, INRAE, UMR IAM, Centre INRAE-Grand Est-Nancy, 54280 Champenoux, \\ Nancy, F-54000, France. \\ ${ }^{2}$ INRAE, UR BEF, Centre INRAE-Grand Est-Nancy, 54280 Champenoux, Nancy, F-54000, France. \\ ${ }^{3}$ Goodell Laboratory, Department of Microbiology, University of Massachusetts, Amherst, MA, United \\ States \\ ${ }^{4}$ Norwegian Institute of Bioeconomy Research (NIBIO), Division of Forests and Forest Resources, \\ Wood Technology, 1431 Ås, Norway
}

\section{Summary:}

In forests ecosystems, fungi and bacteria are key actors in wood degradation. However, few studies have focused on the impact of fungal pre-degradationon bacterial and fungal communities. Coniferous forests are dominated by Brown rot fungi that are involved in earliest phase of lignocellulose breakdown, and therefore, influencing the second phase of microbial colonization. This study aimed to investigate the first microbial species colonizing after intermediate and advanced pre-degradation by the brown rot fungus Gloeophyllum trabeum. Using Illumina metabarcoding, bacterial and fungal communities were monitored after 70 days from Picea abies wood blocks placed between forest floor and topsoil. Chemical composition of the wood samples was determined for each of the pre-degradation stages. We observed significant changes in the bacterial and fungal communities associated with the pre-degradation of $P$. abies, and that wood substrate condition acted as a gatekeeper for both microbial communities. Our data also suggested that fungal and bacterial communities could interact and act in a synergistic way during the wood decomposition process.

\section{Introduction:}

Forests covers $\sim 30 \%$ of global terrestrial area but forest soils account for more than $50 \%$ of the total soil organic C stocks (Carvalhais et al., 2014). In forest ecosystems, coarse woody debris is the primary source of biomass for soil organic matter (SOM) formation. It is composed primarily of polysaccharides and lignin at 65-80\% and 20-35\% (Mao et al., 2019) respectively. The wood-rotting Basidiomycota fungi play a central role in woody litter degradation. They are the major players able to remove or circumvent the lignin barrier that hinders access to plant polysaccharides, which are the major plant components that can support microbial growth (Arantes \& Goodell, 2014). Although it is recognized that there is intergradation in the different types of wood decay which can occur (Riley et al., 2014), the decay fungi are typically categorized into two distinct but related functional groups of Basidiomycota: the brown rot and white rot fungi (Floudas et al., 2012). Indeed, the emergence of the brown rot lineage is reported to be the result of multiple evolutionary events stemming from white rot ancestors with the contraction of gene families involved in lignin decomposition (Floudas et al.,2012; Nagy et al., 2017). White rot fungi are sub-divided into species able to degrade cellulose, hemicelluloses and lignin simultaneously, and species which selectively depolymerize lignin before polysaccharide part, primarily using enzymatic systems. Brown rot fungi employ a different biodegradative strategy and they can remove the carbohydrate from plant tissues by disrupting and then leaving a residue of modified lignin. The brown rot fungi generate hydroxyl radicals 
via what has been described as a chelator-mediated Fenton (CMF) reaction (Goodell et al., 2020). These hydroxyl radicals depolymerize lignin, which then allows polysaccharides to diffuse out of the cell wall where fungal enzymes would primarily be located (Goodell et al. 2017; Zhu et al., 2020) and may also provide greater accessibility of enzymes to the wood cell wall depending on what species of wood and fungi are involved (Arantes \& Goodell , 2014; Goodell et al., 2017; Presley et al., 2018).

The order and timing of species colonization of wood residues during community assembly can affect species abundances and functional diversity, affecting wood decay rate (Fukami et al., 2015Zhang et al., 2016; Zhang et al., 2019)). Relative to the decay of wood in soils, the ability of the microbial community to establish, and how this is impacted by the intrinsic properties of the ecosystem, is also very important relative to the successional establishment of primary and secondary microbial species (Zhalnina et al., 2014; LopezMondejar et al., 2015; Dickie et al., 2012; Hiscox et al., 2016). In living trees, the presence of wood-decay fungi has been observed, meaning that deadwood can already be well colonized by fungi before it falls to the forest floor (Boddy et al., 2001). In contrast, Johnston et al. (2016) suggested that deadwood bacteria are not endophytes but establish primarily from soil contact, and would therefore be selected by associated primary fungi. The importance of the primary fungal colonizer is underlined by several field experiments where the presence of different decay fungi in wood both filtered and regulated the establishment of secondary microbial communities (Hiscox et al., 2015; Hiscox et al., 2016; Jonhston et al., 2019; Christofides et al., 2019).

Recently, Viotti et al. (2021) highlighted the different bacterial and fungal community structure dynamics occurring between oak sapwood and heartwood, suggesting that wood physiochemical properties are important in the microbial assemblage history. Indeed, wood decay rates were correlated with the chemical composition of wood, and decay was strongly reduced both by lignin and extractives content (Kahl et al., 2017). Heartwood extractives are known to have a composition and level of antifungal activity that varies widely within tree species (Valette et al., 2017). This variability influences the colonization of wood by fungi that must detoxify these molecules (Perrot et al., 2020). Consequently, wood physiochemical properties are important drivers of microbial wood colonization and influence, especially the establishment of the pioneer organisms in succession. Thus, during wood degradation processes, both fungi and bacteria modify wood physiochemical properties, and particularly in heartwood, they must first employ their secreted metabolites to cope with extractive molecules and then follow this by enabling cellular machinery which can degrade major wood cell wall polymers.

While some studies have already addressed the influence of primary colonizing fungi on bacterial or fungal colonization strategies, little attention has been paid to examining joint fungal-bacterial colonization and succession. Most studies have focused on the primary colonizing organisms and not on the chemical properties of the decaying wood substrate (Folman et al., 2008; Hervé et al., 2014; Hiscox et al., 2016; Jonhston et al., 2019; Christofides et al., 2019). To help fill this knowledge gap, we carried out a soil incubation using Norway spruce (Picea abies) blocks with pure cultures of the brown rot fungus Gloeophyllum trabeum to produce spruce blocks decayed to different degrees. This aim to reproduce the effect of fungal community dominated by brown rot fungi during the early stages of wood decay in coniferous forest (Ottosson et al., 2013). The spruce blocks were then transferred to unsterile soil; buried in the forest floor of a Norway spruce forest in NE France and incubated for 70 days. We hypothesized that both fungal and bacterial secondary colonizers would attack the wood differently depending on the stage of wood decay introduced to the forest soil. To assess this, fungal and bacterial communities in the blocks were monitored over time using high-throughput amplicon sequencing. We also investigated whether the secondary decomposers originated 
from the forest floor or from the litter, and observed putative fungi/bacteria interactions using coincident data pattern assessment.

\section{Results}

Chemical composition of Norway spruce pre-degraded by Gloeophyllum trabeum prior in situ incubation

Laboratory decay (pre-degradation) of Norway spruce by the brown rot fungus G. trabeum induced substrate mass loss and changes in wood biochemistry (Table S1; Fig. 1). Mass loss increased with pre-degradation duration, but was quite variable (Fig. 1A). For example, $8.1 \pm$ $1.9,15.2 \pm 8.4$ and $24.4 \pm 4.7 \%$ of the initial wood mass was lost after 40, 105 and 165 days of pre-degradation decay, respectively. Pre-degradation by G. trabeum also resulted in a relative decrease in polysaccharides, with a relative increase in both the soluble components and in lignin; which is in accordance with the mechanisms employed by brown rot fungi (Green \& Highley, 1997; Arantes \& Goodell, 2014; Bader et al., 2012). Wood blocks were grouped according to their mass loss (independent of their preincubation time) as either: non-decayed wood $(0 \%, \mathrm{n}=6)$, intermediate decayed wood $(13.36 \pm 0.17 \%, \mathrm{n}=6)$ or advanced decayed wood $(31.71 \pm 1.07 \%, \mathrm{n}=6)$ (Table S1; Fig. 1B).

Norway spruce decay stages decreased microbial diversity and shaped the structure of microbial communities

After 70 days of burial in litter on the forest floor, no additional mass loss was observed in any of the three wood groups beyond the mass loss observed during the laboratory pre-decay period.

The diversity analysis of the bacteria colonizing the pre-degraded wood blocks based on 31 samples was successfully sequenced and provided 1,204,722 high quality reads $(554,534$ sequences for the incubated wood blocks, 323,776 sequences for the forest floor, and 288,031 sequences for the forest soil). Colonizing fungi diversity analysis was based on 29 samples, which provided 1,201,401 high quality reads (575,581 sequences for the incubated wood blocks, 356,480 sequences for the forest floor and 269,340 sequences for the forest soil). Sequences were rarified at 3,488 and 2,886 per sample and distributed into 582 OTUs for bacteria and 526 for fungi. Alpha microbial diversity was assessed using the Chao1 richness estimator, Shannon's diversity index and Pielou's evenness index and all were significantly influenced by the wood, forest floor or soil environment (Fig. 2A and 2B). Wood environments significantly reduced bacterial and fungal richness in comparison to soil and forest floor, independent of the pre-degradation stages. Moreover, pre-degradation of Norway spruce by $G$. trabeum induced a decrease in both bacterial and fungal diversity compared to the other environments (Fig. 2A and 2B).

Bacterial and fungal community structure was strongly influenced by the substrate environment (Fig. 3). Indeed, the change of ecological niche explains $48 \%$ of the variance in the OTU composition respectively for bacteria (Fig. 3A) and $51 \%$ for fungi (Fig. 3B). PERMANOVA analysis confirmed that wood environments (non-decayed wood, intermediate and advanced decay wood) significantly impacted bacterial $\left(R^{2}=0.27, P<0.001\right)$ and fungal $\left(R^{2}=0.35, P<0.001\right)$ communities compared to the soil and forest floor. Inside wood environments, pre-degradation of Norway spruce explained around $32 \%$ of the variance in OTU composition for bacteria and fungi. Although, pre-degradation of Norway spruce by G. trabeum influenced the overall structure of both bacterial and fungal diversity compared to the other 
environments, no major difference in microbial community structure was observed between intermediate and advanced wood decay. This indicates that initial colonization of the predegraded blocks, once moved to the forest floor, thus appears to play an important role in maintaining an established colony. It should be noted that the bulk of $G$. trabeum mycelium from the pre-degradation phase would have been killed in the drying phase of the blocks prior to installation at the forest site.

Bacteria and fungi taxonomic composition in pre-degraded Norway spruce and forest litter differed from that in the forest soil

Differences in fungal and bacterial taxonomic composition highlighted the strong influence of environment on relative microbial abundance (Fig. 4A and B).

Fungal Phyla were dominated by Ascomycota in non-decayed wood, intermediate decay wood, advanced decay wood and in the forest floor. Conversely, Ascomycota and Basidiomycota were almost equally distributed in soil. Interestingly, more Ascomycota were present in non-decayed and intermediate pre-degraded wood compared to soil and forest litter, and Ascomycota increased further still in advanced pre-degraded wood (Fig. 4C). The changes were also observed at the class level: the forest floor was dominated by Leotiomycetes (65\%), soil was primarily colonized by Agaricomycetes (48\%) and Leotiomycetes (29\%), whereas wood environments with non-decayed wood, intermediate decay wood and advanced decay wood were settled by Sordariomycetes $(40 \pm 21 \%)$ and Leotiomycetes (29 $\pm 14 \%)$ (Fig. 4A). The classes with a lower abundance were also influenced by the environment since all wood types were enriched by Tremellomycetes, Eurotiomycetes and Microbotryomycetes classes in comparison to forest floor and soil (Table S2). Interestingly, a potential shift in Basidiomycota classes was observed between Agaricomycetes in non-decayed wood to Tremellomycetes in both intermediate decay and advanced decay wood (Fig. 4A). The Tremellomycetes are characterized as fungal parasites and their presence in the pre-degraded samples is consistent with this fungal lifestyle. Non-decayed wood was the only environment with Mortierellomycetes (Fig. 4A). At the Genus level, wood environments were enriched in several genera such as Penicillium, Scleroconidioma, Cadophora, Krasilnikovozyma, Oidiodendron or Kendrickiella compared to the soil and forest floor sampling. The domination of the Trichoderma genus in non-decayed wood was reinforced in the intermediate and advanced predegraded wood showing the influence of the pre-degradation. Moreover, intermediate decay and advanced pre-degraded wood showed an enrichment in Saitozyma and an impoverishment in Tylospora and Mortierella in comparison to non-decayed wood (Table S2).

The relative abundance of bacterial classes was dramatically different comparing the pre-degraded wood blocks to the forest soil and litter (Fig. 4B). The forest floor was dominated by the Bacteroidia class (35\%) whereas the major class in soil were Acidobacteriae (18\%), Actinobacteria (15\%), Gammaproteobacteria (13\%), and Bacteroidia (12\%). Wood environments, independently of the decay stages, were populated by a high proportion of Alphaproteobacteria (14\%) and Gammaproteobacteria (37\%). The influence of the predegradation was also observed on less abundant classes with a decrease in the relative abundance of Bacteroidia and Acidobacteriae and an increase of Actinobacteria and Saccharimonadia observed in pre-degraded wood in comparison to control wood (Fig. 4B). The influence of these different environments was also found at the family level (Table S2). The forest floor contained the largest amount of Sphingobacteriaceae (27\%), with other environments containing less of this family. Wood environments were dominated by several other families such as Burkholderiaceae and Microbacteriaceae in comparison to soil and litter. Bacterial abundance was also influenced by the pre-degradation stage with Burkholderiaceae over-represented in the intermediate- (34\%) and advanced- (39\%) pre-degraded wood 
compared to non-decayed control wood (9\%), whereas Microbacteriaceae was found in greater proportion in the intermediate- (7\%) and advanced- (19\%) pre-degraded wood compared to non-decayed control wood (1\%) (Table S2). Moreover, wood pre-degradation also positively influenced the abundance of other families such as and Acetobacteraceae, and reduced the presence of Sphingobacteriaceae, Acidobacteriaceae and Sphingomonadaceae families (Table S2).

\section{Bacterial and fungal guild composition}

Despite many OTUs that could not be assigned to any guild, a higher proportion of copiotroph bacteria compared to oligotroph bacteria, were observed in all environments (Fig. 4D). Although, the percentages of copiotrophic bacteria were equivalent (around 54 - 64\%) when comparing forest floor, non-decayed wood, intermediate decay wood and advanced decay pre-degraded wood, the soil showed a lower proportion of copiotrophs with only $32 \%$ (Fig. 4D). The increased number of copiotropic bacteria corresponded to a lower relative abundance of Alphaproteobacteria, Gammaproteobacteria and Bacteroidia in soil than in other environments (Fig. 4B). Moreover, the relative abundance of oligotrophic bacteria in intermediate and advanced pre-degraded wood (around 3\%) was reduced compare to the forest floor, soil, and non-decayed wood (respectively ranging from 13 to 18\%) (Fig. 4D). This could be explained by a significant decrease in Acidobacteriae in intermediate decay wood and in advanced decay pre-degraded wood (Fig. 4B). Interestingly, the type of environment seemed to play a role in the bacterial guild composition with soil having strongly reduced copiotrophic bacteria populations whereas intermediate and advanced pre-degraded wood having proportionally decreased oligotrophic bacteria.

The analysis of fungal guilds highlights the different ecological compositions of both environments (Fig. 4C), even given that up to $50 \%$ of the OTUs were unassigned in the soil, forest floor and intermediate decay wood environments. Among the assigned OTUs, the forest floor was dominated by saprotrophs $(25 \%)$, the soil population consisted primarily of plant pathogens (19\%) and saprotrophs (17\%), wood environments with non-decayed wood, intermediate decay wood and advanced decay wood were represented by saprotrophs at $44 \%$, $28 \%$ and $68 \%$ respectively. This ecological guild was dominated by soft rot at $21 \%, 22 \%$ and $61 \%$ respectively for non-decayed wood, intermediate decay wood and advanced decay wood (Fig. 4C). All wood types showed a higher proportion of soft rot when compared to the soil and forest floor, and advanced wood decay seemed to strongly favor colonization by this fungal guild. This phenomenon corresponded to an increase in the relative abundance of Sordariomycetes (Fig. 4A). An important variation was also observed for saprotrophic organisms, with their presence being reduced in the intermediate $(6 \%)$, and advanced (7\%) predegradation blocks in comparison to non-decayed samples (22\%). Endophyte fungi were only observed in wood environments and confirmed the impact of wood on fungal guild composition (Fig. 4C).

\section{Abundant fungi and bacteria in wood co-occurred in all environments}

Analysis of the most abundant OTUs from the forest floor, soil, non-decayed wood, intermediate decay wood and advanced decay wood showed that 116 bacterial and 128 fungal OTUs displayed at least $1 \%$ abundance in at least one sample. Among the most abundant OTUs, 11 fungal and 30 bacterial OTUs were selected because of their specificity to intermediate and advanced pre-degraded wood samples (Fig. 5B). Their relative abundance in all environments were used in a Spearman rank correlation at the family and species level respectively for bacteria and fungi (Fig. 5). This analysis highlighted a positive correlation $(p<0.001)$ between 
bacterial species belonging to three families: Burkholderiaceae, Microbacteriaceae and Acetobacteraceae, and several fungal species such as Trichoderma spirale, Penicillium aethiopicum, Saitozyma podzolica and Scleroconidioma sphagnicola (Fig. 5A). These results suggest a potential interaction between fungi and bacteria, potentially which may have occurred as part of the wood degradation process. Moreover, when positive correlations between organisms were observed (in all environments) this potentially indicated that specific and potentially positive interactions occurred for the species involved.

\section{Discussion}

In order to study the beginning of the second phase of microbial colonization, we reproduced the early stages of wood decay from coniferous forest with the Norway spruce pre-degradation induced by a brown rot fungus. We demonstrated that the pre-degradation wood decay stages promoted selection of bacterial and fungal communities after samples were transferred to forest floor and forest litter environments. Significant differences in bacterial and fungal communities occurred and these were influenced by both the pre-degradation stage as well as the forest environment. We observed significant differences between wood microbial communities compared to soil and litter, suggesting an important selection pressure by wood.

\section{Pre-degradation of Norway spruce by G. trabeum enhanced selection of competitive fungal species}

Our results demonstrated the influence of Norway spruce pre-degradation by G. trabeum on fungal secondary colonizers. The Trichoderma genus dominated in all wood types, with its proportion increasing as pre-degradation increased to represent around $60 \%$ of total species abundance in the advanced pre-degraded wood samples. Trichoderma spp. on Norway spruce environments is well known for its ability to secrete a variety of CAZymes involved in cellulose degradation (Strakowska et al., 2014; Blaszczyk et al., 2016; Krogh et al., 2004; Isodorov et al., 2016). Trichoderma spp. are also well described to outcompete other microorganisms through the secretion of antifungal compounds, and to use dead mycelia as their carbon-nutrient source (Hiscox et al., 2018; Schuster \& Schmoll, 2010; Gómez-Brandón et al., 2020). Moreover, a shift was observed in Basidiomycota populations from Agaricomycetes in the nondecayed wood to Tremellomycetes in intermediate and advanced pre-degraded wood. Species from Agaricomycetes are described as saprotrophic and as they are involved in wood decay processes (Nguyen et al., 2016). Conversely, species from the Tremellomycetes are described as mycoparasites and possess genes allowing them to recycle carbon from dead mycelia and degraded wood polysaccharides (Kurtzman \& Boekhout, 2017; Oberwinkler \& Lowy, 1981; Kim et al., 2018). Others dominant genera observed in intermediate and advanced decayed wood, included Penicillium and Scleroconidioma, which are known to produce CAZymes involved in some types of cellulose degradation (Koukol \& Kovářová, 2007; Krogh et al., 2004). Overall, the pre-degradation of wood by G. trabeum drove microbial selection toward fungal species involved in lignocellulose degradation and also toward species that could outcompete other organisms, and that utilize live and dead mycelium from other species as a nutrient source. Therefore, depolymerization of the wood cell wall during the pre-degradation phase, as well as the presence of dead mycelium from $G$. trabeum, provided a favorable environment for the establishment and development of these fungal species. 
Bacterial colonization of the intermediate and advanced pre-degraded samples resulted in a decrease of oligotrophic bacteria corresponding with a lower proportion of Acidobacteria. This lead to an increase of the Proteobacteria : Acidobacteria (P/A) ratio suggesting that the high nutrient content, and especially carbon, of the pre-degraded wood aided in this selection (Kielak et al., 2016).

Burkholderiaceae was the most important family in pre-degraded wood. Although this family possesses many genes involved in lignocellulosic degradation, Johnston et al. (2016) reported numerous associations of Burkholderiaceae with fungi suggesting another role for this family in wood decay. Indeed, many species are known to be $\mathrm{N}_{2}$ fixing bacteria and can provide nitrogen essential for fungi (Gómez-Brandón et al., 2020). Moreover, they could also be involved in carbon cycling of lignin breakdown products from fungal activity. They are known to be able to degrade mono-, poly- and heterocyclic aromatic compounds (Morya et al., 2014; Jung et al., 2015; Perez-Pantoja et al., 2012). Others bacterial families were also favored by Norway spruce after pre-degradation, notably species in the Microbacteriaceae family belonging to the Actinobacteria. Interestingly, Viotti et al. (2021) suggested that this family could also be involved in carbon recycling from dead mycelia. Moreover, many of these bacteria are saprophytic and chemoheterotrophic, which allows them to use a wide variety of nutritional sources ranging from polysaccharides to lignin-related aromatic compounds and polymeric lignin, potentially suggesting direct degradation of lignocellulosic material (Barka et al., 2016; Schellenberger et al., 2009; Zimmerman et al., 1990; Wang et al., 2016). Other Actinobacteria have been described as endophytic diazotrophs in Norway spruce logs and could potentially provide nitrogen for fungal activity (Puri et al., 2018).

Additional bacterial families were also enhanced in pre-degraded wood. The Acetobacteraceae family increased in both intermediate- and advanced- pre-degraded wood. This family is known for their capacity to fix nitrogen and for their ability to solubilize phosphorous and zinc (Suman et al., 2001; Saravanan et al., 2007). In wood decomposition processes, access to both nitrogen and phosphorous promoted by bacteria could favor fungal activity. We also observed an increase in species from the Saccharimonadia family belonging to the Patescibacteria phyla. The small size of this family's genomes as well as the description of the epibiotic parasitic lifestyle of the strain TM7x (CPR/Patescibacteria) suggests that the Saccharimonadia may have a symbiotic lifestyle (Lemos et al., 2020; He et al., 2015). Prior research reinforces this concept as a co-occurrence analysis also suggests that Patescibcateria could interact with members affiliated with Bacteroidia, Alphaproteobacteria, Gammaproteobacteria and Actinobacteria species which are abundant in pre-degraded Norway spruce (Lemos et al., 2019).

Overall, the data suggest that the predominant bacteria that established in pre-degraded wood were able to metabolize compounds from the pre-degraded wood, and they also were also able to provide nutrients to the fungi to promote fungal growth. In early wood decay stages, bacteria were not directly involved in lignocellulose degradation but our data suggest that they established in support of fungal activity.

\section{Bacteria and fungi co-occurred in environments under mutualistic interaction}

The abundance of several bacterial families (Burkholderiaceaea, Microbacteriaceae and Acetobacteraceae) showed a positive correlation with two fungal genera (Penicillium and Trichoderma) in all environments. In the context of wood degradation, bacteria could potentially take up carbon from fungal hyphae exudates or lignocellulose degradation products, while at the same time also supplying the fungi with essential nutrients such as nitrogen, phosphorus or zinc (Zhang et al., 2020; Saravanan et al., 2007; Schellenberger et al., 2009; Kirker et al., 2017; Zelinka et al., 2021). Moreover, some bacteria can detoxify antifungal 
compounds and therefor they may also help to synergistically protect fungal species in the same environment (Nazir et al., 2014). In all environments, the co-occurrence of bacteria and fungi may promote the growth and distribution of bacteria. Indeed, in soil, fungal hyphae form a belowground network that specific bacterium have been reported to navigate subject to localized environmental conditions, to promote their migration (Yang $\mathrm{Pu}$ 2017). Soil is a sporadic source of nutrients that are often concentrated in hotspots and ephemerally available. The use of this semi-continuous network by bacteria would enhance their ability to discover new nutrient-rich environments. Bacterial dispersal along fungal hyphae could be the result of mutualistic interactions, with soil inhabiting fungi being known to mobilize pollutant-degrading bacteria with resultant mediation of bacterial diffusion to the polluted sites, thereby enhancing soil bioremediation (Kohlmeier et al., 2005; Furuno et al., 2010). Finally, bacteria and fungi co-exist and interact in a variety of ways to impact their micro-environments in ways that will release nutrients and promote synergistic growth.

\section{Conclusion:}

The pre-degradation of wood by G. trabeum causes an important modification of both bacterial and fungal communities. These communities interact synergistically, i.e, fungi are the main decomposers of organic matter to provide carbon (wood degradation products and fungal hyphal residues and exudates) for bacteria. In-turn, the bacteria provide nutrients (nitrogen, zinc or phosphorous) to the fungi, and protect fungi against antagonistic compounds produced both by other bacteria and invading fungi. In our research, particularly with pre-degraded wood, wood environments promoted a strong decrease in fungal and bacterial communities compared to soil and forest floor environments.

\section{Experimental procedures}

\section{In vitro and field site degradation}

Norway spruce blocks (Picea abies Karst) $(50 \times 25 \times 15 \mathrm{~mm})$ originating from Norwegian forest stands were placed in petri dishes containing malt agar medium and four $7 \mathrm{~mm}$ inoculum plugs of Gloeophyllum trabeum (strain 88913) for decay according to EN 113. Cultures were incubated at $25^{\circ} \mathrm{C}$ for $50,80,105,130,150$ and 165 days and wood mass loss on 3 replicate sacrificial samples was then measured on the dried samples $\left(60^{\circ} \mathrm{C}, 12 \mathrm{~h}\right)$. After laboratory decay exposure (pre-degradation), the wood samples were installed in Spring 2019 at the BreuilChenue experimental forest site, in the Morvan area in France $\left(47^{\circ} 18^{\prime} \mathrm{N}, 4^{\circ} 5^{\prime} \mathrm{E}\right)$. The forest is located on a plateau at $640 \mathrm{~m}$, the annual rainfall is $1280 \mathrm{~mm}$ and the average temperature is $9^{\circ} \mathrm{C}$. The soil is an alocrisol that developed over the 'La Pierre qui Vire' leucogranite with a topsoil pH ranging between 3.8 and 4.5 (Baize \& Girard, 1988; Levrel \& Ranger, 2004)(Table S3). In 1976, a part of the native forest was clear-cut and the area was planted with several mono-specific plantations $\left(1000 \mathrm{~m}^{2}\right.$ for each). Among these, one plot that was planted with Norway spruce was selected for this study. We selected a $90 \times 45 \mathrm{~cm}$ area and carefully removed the forest floor litter layer for placement of bagged wood block samples in a block design on the topsoil as described below. Polyamide bags with a fabric mesh size of $1 \mathrm{~mm}$ were used to each contain a single wood block. Six replicates were used for each treatment including the undecayed control. Treatments included "undecayed controls" ( $0 \%$ laboratory mass loss), "intermediate" decayed samples (13.36 $\pm 0.17 \%$ laboratory mass loss), and "advanced" decay samples $(31.71 \pm 1.07 \%$ laboratory mass loss $)$. The bagged blocks were uniformly distributed throughout the area, covered with the original forest floor litter layer, and then after 70 days these samples were collected. Eight forest floor litter layer samples, and eight soil cores from the $0-5 \mathrm{~cm}$ mineral horizon were also collected (Fig. S1). All samples were transported to the 
laboratory frozen in ice, and then were stored at $-80^{\circ} \mathrm{C}$. Before DNA extraction, samples were comminuted using a cryomill (Retsch $\mathrm{GmbH}$, Germany) following the manufacturer's instructions and three subsamples $(700 \mathrm{mg}$ ) of soil, litter or wood were used for DNA extraction.

\section{Wood biochemistry of Norway spruce}

A modified Van Soest protocol with "Fibrebag" technology (C. Gerhardt GmbH \& Co., Germany) (Van Soest \& Wine, 1967; Van Soest \& McQueen, 1973) was used to filter the solubilized wood polymers during each sequential solvent treatment stage. Briefly summarized, these stages were: 1) Extractives removed first through solubilization using a neutral detergent fiber solution (sodium dodecyl sulfate, sodium EDTA, sodium phosphate monobasic, sodium tetraborate decahydrate and triethylene glycol, with $\mathrm{pH}$ ranging between 6.9 and 7.1). 2) Hemicellulose was then solubilized using an acid detergent fiber solution (CTAB dissolved in 11 of sulfuric acid $0.5 \mathrm{~mol} / \mathrm{l}$ ). 3) Finally, an acid detergent treatment (sulfuric acid, $72 \%$ ) was used to solubilize cellulose, leaving lignin as final product. Each solubilized fraction was collected and dried overnight at $105^{\circ} \mathrm{C}$ before weighing to determine mass loss as compared to undecayed reference samples.

\section{DNA extraction, PCR amplification and sequencing}

Genomic DNA was extracted from $700 \mathrm{mg}$ of comminuted materials (soil, forest floor litter or wood) using a RNeasy powersoil DNA elution kit following the manufacturer's instructions (Qiagen GmbH, Hilden, Germany). No DNA was retrieved from the non-decayed wood samples, so a second "surface extraction" method was then used with the same kit assuming that, in these samples, any microbial colonization would have occurred mainly at the surface of the wood blocks. Using this method, DNA was extracted from surface-etched non-decayed wood blocks with a success rate of $75 \%$. Amplification of the fungal ITS2 region was then performed using forward primer ITS86f (5'-GTGAATCATCGAATCTTTGAA-3') and reverse primer ITS4r (5'-TCCTCCGCTTATTGATAGTC-3')(Op De beeck et al., 2014). For bacterial communities, the $16 \mathrm{~S}$ rRNA V4 region was amplified with forward primer $515 \mathrm{f}\left(5^{\prime}\right.$ GTGCCAGCMGCCGCGGTAA-3') and reverse primer 806r (5'GGACTACHVGGTWTCTAAT-3') (Caporaso et al., 2011). For each DNA extraction, three independent PCR reactions were carried out in a final volume of $50 \mu 1$ with Herculase II fusion DNA polymerase (Agilent), then pooled and confirmed on gel electrophoresis for both fungi and bacteria. The PCR conditions used were $95^{\circ} \mathrm{C}$ for $3 \mathrm{~min}, 33$ cycles of $45 \mathrm{~s}$ at $95^{\circ} \mathrm{C}$ (denaturation), $55^{\circ} \mathrm{C}$ for $30 \mathrm{~s}$ (annealing) and $72^{\circ} \mathrm{C}$ for $30 \mathrm{~s}$ (extension), followed by $10 \mathrm{~min}$ $72^{\circ} \mathrm{C}$. The multiplexed and the Illumina MiSeq sequencing were performed by Genoscreen Society (Lille, France, https://www.genoscreen.fr/fr/). The raw MiSeq sequences were submitted to the Sequence Read Archive (SRA) and are available under the BioProject ID: PRJNA775075.

\section{Miseq sequences processing and bioinformatic analyses}

Sequences were demultiplexed with CASAVA v1.0 software (script PERL ConfigureBclToFastq.pl) and merged with a FLASH tool configured to suppress the PCR 
primer ( $100 \%$ of identity), to trim extremities with a score $\leq$ Q30, and to maintain a minimal length of 30 nucleotides with an identity yield of $97 \%$ (Magoc \& Salzberg, 2011). The paired sequences (read 1 and read 2 merged) were then processed with FROGS pipeline (Galaxy Solutions from Genotoul Bioinformatic platform http://frogs.toulouse.inra.fr) (Escudié et al., 2018). Briefly, dereplicated sequences were clustered with Swarm (aggregation parameters equal 1), chimera detection and deletion was based on VSEARCH using the de novo UCHIME method, and sequences were then filtered to keep the minimum number of operational taxonomy units (OTUs) below 0.00005 (Mahe et al., 2014; Edgar et al., 2010; Rognes et al., 2016; Bokulich et al., 2013). Sequence affiliation was done using a basic local alignment search tool (BLAST) on silva138_ pintail100 16S database for bacterial sequences and Unite_Fungi_8.2_20200204 database for fungal sequences and a sequence aggregation step was then performed using $98 \%$ of identity and a coverage of $98 \%$. For fungal data G. trabeum sequences were removed. The number of sequences per sample was normalized by random sampling to 2,886 and 3,488 respectively for fungi and bacteria (Table S4). Bacterial OTUs belonging to several proteobacteria classes (alpha, beta and gamma) or the Bacteroidetes phylum were assigned as copiotrophs, whereas deltaproteobacteria and acidobacteria were categorized as oligotrophic organisms (Fierer et al., 2007). The trophic mode of fungal OTUs was assigned using FUNGuild (Nguyen et al., 2016). Fungi were parsed between saprotroph, pathogenic, symbiotrophic respectively sub-divided in soft rot and white rot fungi, in plant or animal pathogens and fungal parasites, and in endophytes, ericoid mycorrhizal and ectomycorrhizal fungi. Another guild was created to regroup all OTU potentially corresponding to "yeast" (Viotti et al., 2021).

\section{Statistical analyses}

Statistical analyses and data visualization were performed with $\mathrm{R}$ using phyloseq and ggplot2 packages (Mcmurdie \& Holmes, 2013). OTU richness and Shannon's index were determined using a Phyloseq package (https://rdrr.io/bioc/phyloseq/man/phyloseq-package.html), and Pielou's evenness was then calculated according to the formula present in the vegan package (Oksanen et al., 2019). Following this, pairwise comparisons using the Wilcoxon rank sum test were performed to determine differences between environments. Differences in bacterial and fungal OTU composition were visualized with principal coordinates analyses (PCoA) on Unirac distance matrices using the plot_ordination function in the Phyloseq package. PCoA was used rather than principal components analysis to better reflect the 2-D distance between samples. Permutational multivariate analysis of variance (PERMANOVA) was performed on Unifrac matrices using the Adonis function of the vegan package in order to determine the effect of wood on the bacterial and fungal community structures as well as measuring the impact of degradation inside wood environments. Bacterial and fungal co-occurrence was analyzed using the Corrplot package in $\mathrm{R}$ by selecting the Spearman correlation and recognizing only significant values ( $\mathrm{p}$ value $<0.001$ ).

\section{Acknowledgements}

This work was supported by the Laboratory of Excellence Arbre (ANR-11-LABEX-0002-01; BRAWO project). The UMR1136 and the UR1138 are supported by the French Agency through the Laboratory of Excellence Arbre (ANR- 11-LABX-0002-01). Goodell was supported by the National Institute of Food and Agriculture, U.S. Department of Agriculture, the Center for Agriculture, Food and the Environment, and the Microbiology department at University of Massachusetts Amherst, under project number S1075 - MAS00503. Alfredsen was supported by the NIBIO strategic project 11077 . The contents are solely the responsibility of the authors and do not necessarily represent the official views of the USDA or NIFA. The 
Breuil-Chenue site belongs to French national research infrastructure ANAEE-France (ANR11-INBS-0001). We gratefully acknowledge the financial support received successively from GIP ECOFOR, AllEnvi, ANAEE France, the LTSER Zone Atelier Bassin Moselle and INRAE (DISC, ECODIV). We would also like to thank l'Office National des Forêts, the Parc Naturel Régional du Morvan and Serge Didier for his contribution to the Breuil-Chenue site management.

\section{References}

Arantes, V. and Goodell, B. (2014) Current Understanding of Brown-Rot Fungal Biodegradation Mechanisms: A Review. In ACS Symposium Series. Schultz, T.P., Goodell, B., and Nicholas, D.D. (eds). Washington, DC: American Chemical Society, pp. 3-21.

Bader, T.K., Hofstetter, K., Alfredsen, G., and Bollmus, S. (2012) Changes in microstructure and stiffness of Scots pine (Pinus sylvestris L) sapwood degraded by Gloeophyllum trabeum and Trametes versicolor - Part II: Anisotropic stiffness properties. Holzforschung 66:.

Baize, D. and Girard, M. C. (1988) Référentiel pédologique francais.

Barka, E.A., Vatsa, P., Sanchez, L., Gaveau-Vaillant, N., Jacquard, C., Klenk, H.-P., et al. (2016) Taxonomy, Physiology, and Natural Products of Actinobacteria. Microbiol Mol Biol Rev 80: 143.

Błaszczyk, L., Strakowska, J., Chełkowski, J., Gąbka-Buszek, A., and Kaczmarek, J. (2016) Trichoderma species occurring on wood with decay symptoms in mountain forests in Central Europe: genetic and enzymatic characterization. J Appl Genetics 57: 397-407.

Boddy, L. (2001) Fungal Community Ecology and Wood Decomposition Processes in Angiosperms: From Standing Tree to Complete Decay of Coarse Woody Debris. Ecological Bulletins 43-56.

Bokulich, N.A., Subramanian, S., Faith, J.J., Gevers, D., Gordon, J.I., Knight, R., et al. (2013) Qualityfiltering vastly improves diversity estimates from Illumina amplicon sequencing. Nat Methods 10: $57-59$.

Caporaso, J.G., Lauber, C.L., Walters, W.A., Berg-Lyons, D., Lozupone, C.A., Turnbaugh, P.J., et al. (2011) Global patterns of 16S rRNA diversity at a depth of millions of sequences per sample. Proceedings of the National Academy of Sciences 108: 4516-4522.

Carvalhais, N., Forkel, M., Khomik, M., Bellarby, J., Jung, M., Migliavacca, M., et al. (2014) Global covariation of carbon turnover times with climate in terrestrial ecosystems. Nature 514: 213217.

Christofides, S.R., Hiscox, J., Savoury, M., Boddy, L., and Weightman, A.J. (2019) Fungal control of early-stage bacterial community development in decomposing wood. Fungal Ecology 42: 100868.

Dickie, I.A., Fukami, T., Wilkie, J.P., Allen, R.B., and Buchanan, P.K. (2012) Do assembly history effects attenuate from species to ecosystem properties? A field test with wood-inhabiting fungi: Assembly history effects. Ecology Letters 15: 133-141.

Edgar, R.C. (2010) Search and clustering orders of magnitude faster than BLAST. Bioinformatics 26: 2460-2461.

Escudié, F., Auer, L., Bernard, M., Mariadassou, M., Cauquil, L., Vidal, K., et al. (2018) FROGS: Find, Rapidly, OTUs with Galaxy Solution. Bioinformatics 34: 1287-1294.

Fierer, N., Bradford, M.A., and Jackson, R.B. (2007) TOWARD AN ECOLOGICAL CLASSIFICATION OF SOIL BACTERIA. Ecology 88: 1354-1364.

Floudas, D., Binder, M., Riley, R., Barry, K., Blanchette, R.A., Henrissat, B., et al. (2012) The Paleozoic Origin of Enzymatic Lignin Decomposition Reconstructed from 31 Fungal Genomes. Science 336: $1715-1719$. 
Folman, L.B., Klein Gunnewiek, P.J.A., Boddy, L., and De Boer, W. (2008) Impact of white-rot fungi on numbers and community composition of bacteria colonizing beech wood from forest soil: Impact of white-rot fungi on bacteria colonizing wood. FEMS Microbiology Ecology 63: 181191.

Fukami, T. (2015) Historical Contingency in Community Assembly: Integrating Niches, Species Pools, and Priority Effects. Annu Rev Ecol Evol Syst 46: 1-23.

Furuno, S., Päzolt, K., Rabe, C., Neu, T.R., Harms, H., and Wick, L.Y. (2009) Fungal mycelia allow chemotactic dispersal of polycyclic aromatic hydrocarbon-degrading bacteria in waterunsaturated systems. Environmental Microbiology.

Gómez-Brandón, M., Probst, M., Siles, J.A., Peintner, U., Bardelli, T., Egli, M., et al. (2020) Fungal communities and their association with nitrogen-fixing bacteria affect early decomposition of Norway spruce deadwood. Sci Rep 10: 8025.

Goodell, B. (2020) 15 Fungi Involved in the Biodeterioration and Bioconversion of Lignocellulose Substrates. In Genetics and Biotechnology. Benz, J.P. and Schipper, K. (eds). Cham: Springer International Publishing, pp. 369-397.

Goodell, B., Zhu, Y., Kim, S., Kafle, K., Eastwood, D., Daniel, G., et al. (2017) Modification of the nanostructure of lignocellulose cell walls via a non-enzymatic lignocellulose deconstruction system in brown rot wood-decay fungi. Biotechnol Biofuels 10: 179.

Green, F. and Highley, T.L. (1997) Mechanism of brown-rot decay: Paradigm or paradox. International Biodeterioration \& Biodegradation 39: 113-124.

He, X., McLean, J.S., Edlund, A., Yooseph, S., Hall, A.P., Liu, S.-Y., et al. (2015) Cultivation of a human-associated TM7 phylotype reveals a reduced genome and epibiotic parasitic lifestyle. Proc Natl Acad Sci USA 112: 244-249.

Hervé, V., Le Roux, X., Uroz, S., Gelhaye, E., and Frey-Klett, P. (2014) Diversity and structure of bacterial communities associated with $P$ hanerochaete chrysosporium during wood decay: Bacteria of the white-rot mycosphere. Environ Microbiol 16: 2238-2252.

Hiscox, J., Clarkson, G., Savoury, M., Powell, G., Savva, I., Lloyd, M., et al. (2016) Effects of precolonisation and temperature on interspecific fungal interactions in wood. Fungal Ecology 21: $32-42$.

Hiscox, J., O'Leary, J., and Boddy, L. (2018) Fungus wars: basidiomycete battles in wood decay. Studies in Mycology 89: 117-124.

Hiscox, J., Savoury, M., Johnston, S.R., Parfitt, D., Müller, C.T., Rogers, H.J., and Boddy, L. (2016) Location, location, location: priority effects in wood decay communities may vary between sites: Location and priority effects in fungi. Environ Microbiol 18: 1954-1969.

Isidorov, V., Tyszkiewicz, Z., and Pirożnikow, E. (2016) Fungal succession in relation to volatile organic compounds emissions from Scots pine and Norway spruce leaf litter-decomposing fungi. Atmospheric Environment 131: 301-306.

Johnston, S.R., Boddy, L., and Weightman, A.J. (2016) Bacteria in decomposing wood and their interactions with wood-decay fungi. FEMS Microbiology Ecology 92: fiw179.

Johnston, S.R., Hiscox, J., Savoury, M., Boddy, L., and Weightman, A.J. (2019) Highly competitive fungi manipulate bacterial communities in decomposing beech wood ( Fagus sylvatica ). FEMS Microbiology Ecology 95:.

Jung, D.-H., Kim, E.-J., Jung, E., Kazlauskas, R.J., Choi, K.-Y., and Kim, B.-G. (2016) Production of $p$ - hydroxybenzoic acid from $p$ - coumaric acid by Burkholderia glumae BGR1: Production of $p$-Hydroxybenzoate by B. glumae. Biotechnol Bioeng 113: 1493-1503.

Kahl, T., Arnstadt, T., Baber, K., Bässler, C., Bauhus, J., Borken, W., et al. (2017) Wood decay rates of 13 temperate tree species in relation to wood properties, enzyme activities and organismic diversities. Forest Ecology and Management 391: 86-95.

Kielak, A.M., Barreto, C.C., Kowalchuk, G.A., van Veen, J.A., and Kuramae, E.E. (2016) The Ecology of Acidobacteria: Moving beyond Genes and Genomes. Front Microbiol 7:. 
Kim, J.-Y., Jang, J.H., Park, J.-H., Jung, H.-Y., Park, J.-S., Cho, S.-J., et al. (2018) 한국의 메뚜기의 장에서 분리된 Cellulose를 분해하는 담자균 효모. 한국미생물학회지 54: 362-368.

Kirker, G., Zelinka, S., Gleber, S.-C., Vine, D., Finney, L., Chen, S., et al. (2017) Synchrotron-based $\mathrm{X}$-ray fluorescence microscopy enables multiscale spatial visualization of ions involved in fungal lignocellulose deconstruction. Sci Rep 7: 41798.

Kohlmeier, S., Smits, T.H.M., Ford, R.M., Keel, C., Harms, H., and Wick, L.Y. (2005) Taking the Fungal Highway: Mobilization of Pollutant-Degrading Bacteria by Fungi. Environ Sci Technol 39: 4640-4646.

Koukol, O. and Kovářová, M. (2007) Autecology of Scleroconidioma sphagnicola particularly in Šmava National Park (Czech Republic). Czech Mycol 59: 111-123.

Krogh, K. B., Mørkeberg, A., Jørgensen, H., Frisvad, J. C., \& Olsson, L. (2004). Screening genusPenicillium for producers of cellulolytic and xylanolytic enzymes. Proceedings of the Twenty-Fifth Symposium on Biotechnology for Fuels and Chemicals Held May 4-7, 2003, in Breckenridge, CO (pp. 389-401). Humana Press, Totowa, NJ.

Kurtzman, C.P. and Boekhout, T. (2017) Yeasts as Distinct Life Forms of Fungi. In Yeasts in Natural Ecosystems: Ecology. Buzzini, P., Lachance, M.-A., and Yurkov, A. (eds). Cham: Springer International Publishing, pp. 1-37.

Lemos, L., Manoharan, L., Mendes, L., Venturini, A., Pylro, V., and Tsai, S.M. (2020) Metagenome assembled-genomes reveal similar functional profiles of CPR /Patescibacteria phyla in soils. Environmental Microbiology Reports 12: 651-655.

Lemos, L.N., Medeiros, J.D., Dini-Andreote, F., Fernandes, G.R., Varani, A.M., Oliveira, G., and Pylro, V.S. (2019) Genomic signatures and co-occurrence patterns of the ultra-small Saccharimonadia (phylum CPR/Patescibacteria) suggest a symbiotic lifestyle. Mol Ecol 28: 4259-4271.

Levrel, G., and Ranger, J. (2006) Effet des substitutions d'essences forestières et des

amendements sur les propriétés physiques d'un Alocrisol. Site expérimental de la forêt de BreuilChenue, Morvan, France. Étude et Gestion des Sols 13 : 71-88.

López-Mondéjar, R., Voříšková, J., Větrovský, T., and Baldrian, P. (2015) The bacterial community inhabiting temperate deciduous forests is vertically stratified and undergoes seasonal dynamics. Soil Biology and Biochemistry 87: 43-50.

Magoc, T. and Salzberg, S.L. (2011) FLASH: fast length adjustment of short reads to improve genome assemblies. Bioinformatics 27: 2957-2963.

Mahé, F., Rognes, T., Quince, C., de Vargas, C., and Dunthorn, M. (2014) Swarm: robust and fast clustering method for amplicon-based studies. PeerJ 2: e593.

Mao, Z., Derrien, D., Didion, M., Liski, J., Eglin, T., Nicolas, M., et al. (2019) Modeling soil organic carbon dynamics in temperate forests with Yasso07. Biogeosciences 16: 1955-1973.

McMurdie, P.J. and Holmes, S. (2013) phyloseq: An R Package for Reproducible Interactive Analysis and Graphics of Microbiome Census Data. PLoS ONE 8: e61217.

Morya, R., Salvachúa, D., and Thakur, I.S. (2020) Burkholderia: An Untapped but Promising Bacterial Genus for the Conversion of Aromatic Compounds. Trends in Biotechnology 38: 963-975.

Nagy, L.G., Riley, R., Bergmann, P.J., Krizsán, K., Martin, F.M., Grigoriev, I.V., et al. (2017) Genetic Bases of Fungal White Rot Wood Decay Predicted by Phylogenomic Analysis of Correlated Gene-Phenotype Evolution. Mol Biol Evol 34: 35-44.

Nazir, R., Tazetdinova, D.I., and van Elsas, J.D. (2014) Burkholderia terrae BS001 migrates proficiently with diverse fungal hosts through soil and provides protection from antifungal agents. Front Microbiol 5:.

Nguyen, N.H., Song, Z., Bates, S.T., Branco, S., Tedersoo, L., Menke, J., et al. (2016) FUNGuild: An open annotation tool for parsing fungal community datasets by ecological guild. Fungal Ecology 20: 241-248. 
Oberwinkler, F. and Lowy, B. (1981) Syzygospora alba, a Mycoparasitic Heterobasidiomycete. Mycologia 73: 1108.

Oksanen, J., Blanchet, F.G., Friendly, M., Kindt, R., Legendre, P., McGlinn, D., et al.

(2019) Vegan: Community Ecology Package R package version 2.5-6 (2019); https://CRAN.Rproject.org/package= $=$ vegan

Op De Beeck, M., Lievens, B., Busschaert, P., Declerck, S., Vangronsveld, J., and Colpaert, J.V. (2014) Comparison and Validation of Some ITS Primer Pairs Useful for Fungal Metabarcoding Studies. PLOS ONE 9: e97629.

Ottosson, E. Succession of Wood-inhabiting Fungal Communities. 61.

Pérez-Pantoja, D., Donoso, R., Agulló, L., Córdova, M., Seeger, M., Pieper, D.H., and González, B. (2012) Genomic analysis of the potential for aromatic compounds biodegradation in Burkholderiales: Degradation of aromatic compounds in Burkholderiales. Environmental Microbiology 14: 1091-1117.

Perrot, T., Salzet, G., Amusant, N., Beauchene, J., Gérardin, P., Dumarçay, S., et al. (2020) A reverse chemical ecology approach to explore wood natural durability. Microb Biotechnol 13: 16731677.

Presley, G.N., Panisko, E., Purvine, S.O., and Schilling, J.S. (2018) Coupling Secretomics with Enzyme Activities To Compare the Temporal Processes of Wood Metabolism among White and Brown Rot Fungi. Appl Environ Microbiol 84:

Puri, A., Padda, K.P., and Chanway, C.P. (2018) Evidence of endophytic diazotrophic bacteria in lodgepole pine and hybrid white spruce trees growing in soils with different nutrient statuses in the West Chilcotin region of British Columbia, Canada. Forest Ecology and Management 430: 558-565.

Riley, R., Salamov, A.A., Brown, D.W., Nagy, L.G., Floudas, D., Held, B.W., et al. (2014) Extensive sampling of basidiomycete genomes demonstrates inadequacy of the white-rot/brown-rot paradigm for wood decay fungi. Proc Natl Acad Sci USA 111: 9923-9928.

Rognes, T., Flouri, T., Nichols, B., Quince, C., and Mahé, F. (2016) VSEARCH: a versatile open source tool for metagenomics. PeerJ 4: e2584.

Saravanan, V.S., Madhaiyan, M., and Thangaraju, M. (2007) Solubilization of zinc compounds by the diazotrophic, plant growth promoting bacterium Gluconacetobacter diazotrophicus. Chemosphere 66: 1794-1798.

Schellenberger, S., Kolb, S., and Drake, H.L. (2009) Metabolic responses of novel cellulolytic and saccharolytic agricultural soil Bacteria to oxygen: Metabolic response of soil cellulose degraders. Environmental Microbiology 12: 845-861.

Schuster, A. and Schmoll, M. (2010) Biology and biotechnology of Trichoderma. Appl Microbiol Biotechnol 87: 787-799.

Soest, P.J.V. and Wine, R.H. (1967) Use of Detergents in the Analysis of Fibrous Feeds. IV. Determination of Plant Cell-Wall Constituents. Journal of AOAC INTERNATIONAL 50: 50-55.

Strakowska, J., Błaszczyk, L., and Chełkowski, J. (2014) The significance of cellulolytic enzymes produced by Trichoderma in opportunistic lifestyle of this fungus: Cellulases produced by Trichoderma. J Basic Microbiol 54: S2-S13.

Suman, A., Shasany, A.K., Singh, M., Shahi, H.N., Gaur, A., and Khanuja, S.P.S. Molecular assessment of diversity among endophytic diazotrophs isolated from subtropical Indian sugarcane. 7.

Valette, N., Perrot, T., Sormani, R., Gelhaye, E., and Morel-Rouhier, M. (2017) Antifungal activities of wood extractives. Fungal Biology Reviews 31: 113-123.

Van Soest, P.J. and McQueen, R.W. (1973) The chemistry and estimation of fibre. Proc Nutr Soc 32: 123-130.

Viotti, C., Bach, C., Maillard, F., Ziegler-Devin, I., Mieszkin, S., and Buée, M. (2021) Sapwood and heartwood affect differentially bacterial and fungal community structure and successional dynamics during Quercus petraea decomposition. Environ Microbiol 1462-2920.15522. 
Wang, C., Dong, D., Wang, Haoshu, Müller, K., Qin, Y., Wang, Hailong, and Wu, W. (2016) Metagenomic analysis of microbial consortia enriched from compost: new insights into the role of Actinobacteria in lignocellulose decomposition. Biotechnol Biofuels 9: 22.

Yang, P. (2017) Mechanisms of migration of Paraburkholderia terrae BS001 in the mycosphere. Doctoral dissertation, University of Groningen.

Zelinka, S.L., Jakes, J.E., Kirker, G.T., Bishell, A.B., Boardman, C.R., Lai, B., et al. (2021) Oxidation states of iron and manganese in lignocellulose altered by the brown rot fungus Gloeophyllum trabeum measured in-situ using X-ray absorption near edge spectroscopy (XANES). International Biodeterioration \& Biodegradation 158: 105162.

Zhalnina, K., Dias, R., de Quadros, P.D., Davis-Richardson, A., Camargo, F.A.O., Clark, I.M., et al. (2015) Soil pH Determines Microbial Diversity and Composition in the Park Grass Experiment. Microb Ecol 69: 395-406.

Zhang, J., Presley, G.N., Hammel, K.E., Ryu, J.-S., Menke, J.R., Figueroa, M., et al. (2016) Localizing gene regulation reveals a staggered wood decay mechanism for the brown rot fungus Postia placenta. Proc Natl Acad Sci USA 113: 10968-10973.

Zhang, J., Silverstein, K.A.T., Castaño, J.D., Figueroa, M., and Schilling, J.S. (2019) Gene Regulation Shifts Shed Light on Fungal Adaption in Plant Biomass Decomposers. mBio 10:

Zhang, Y., Hao, X., Garcia-Lemos, A.M., Nunes, I., Nicolaisen, M.H., and Nybroe, O. (2020) Different Effects of Soil Fertilization on Bacterial Community Composition in the Penicillium canescens Hyphosphere and in Bulk Soil. Appl Environ Microbiol 86:

Zhu, Y., Plaza, N., Kojima, Y., Yoshida, M., Zhang, J., Jellison, J., et al. (2020) Nanostructural Analysis of Enzymatic and Non-enzymatic Brown Rot Fungal Deconstruction of the Lignocellulose Cell Wall†. Front Microbiol 11: 1389.

Zimmermann, W. (1990) Degradation of lignin by bacteria. Journal of Biotechnology 13:

119-130. 

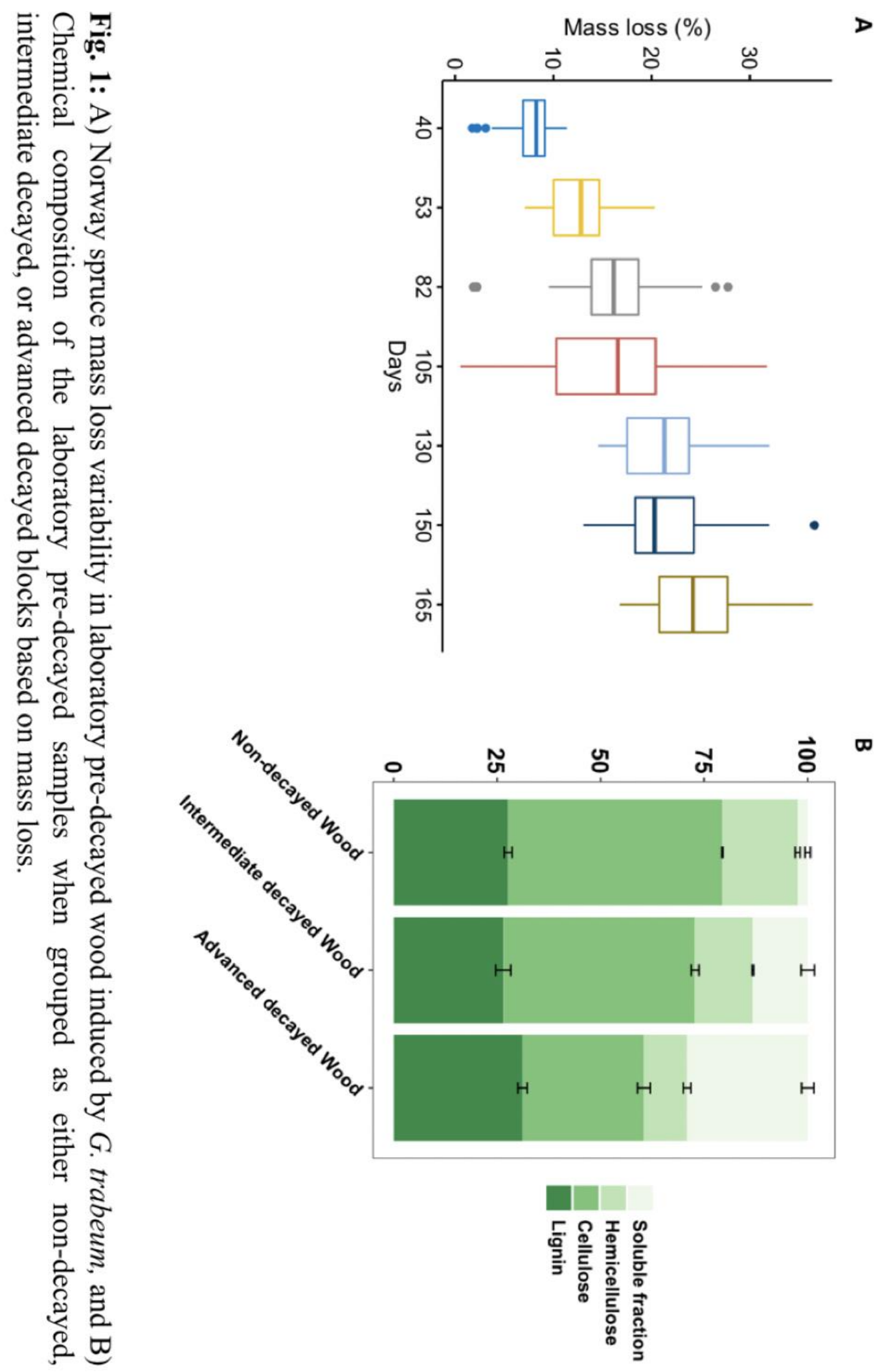

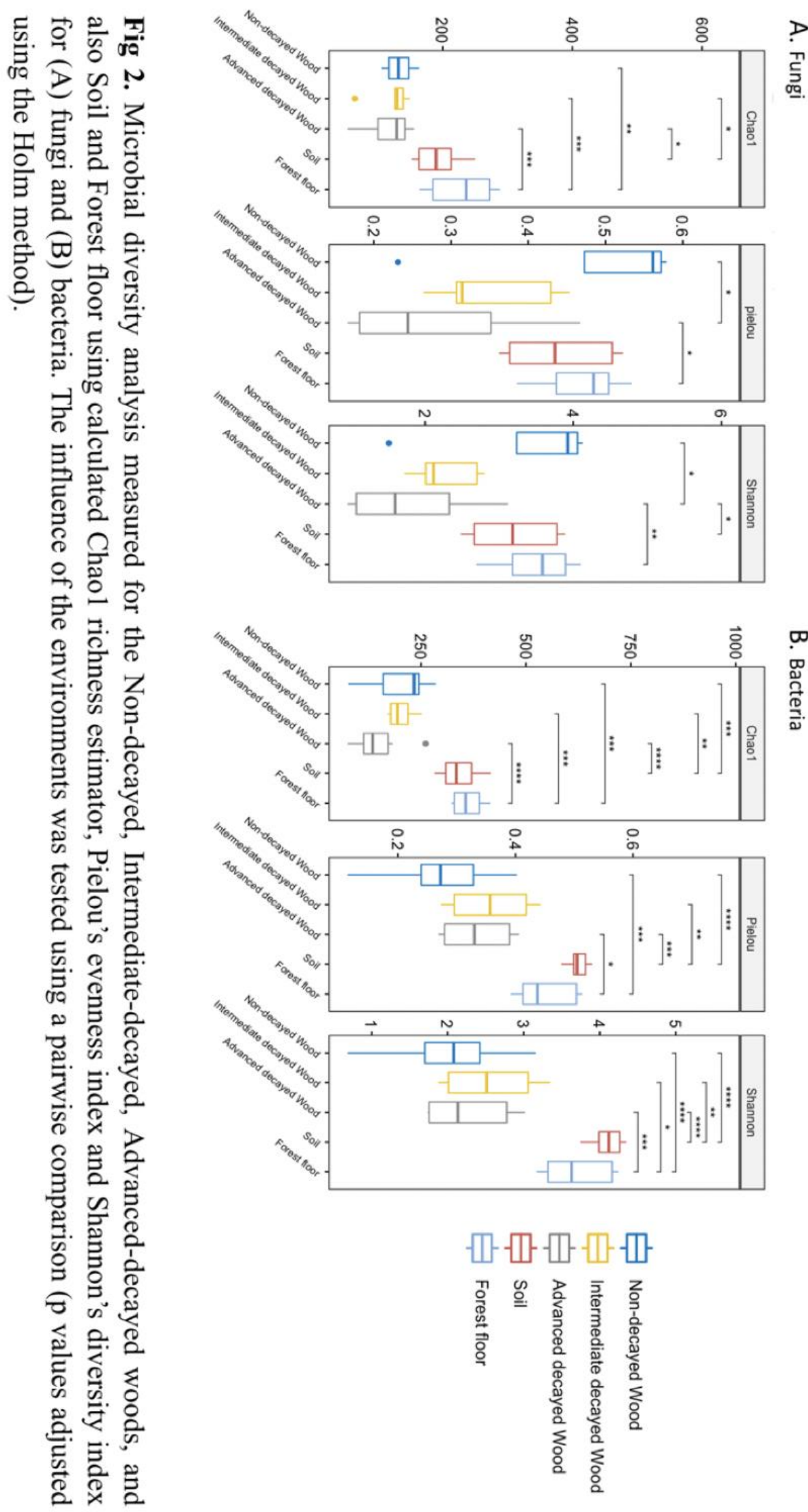


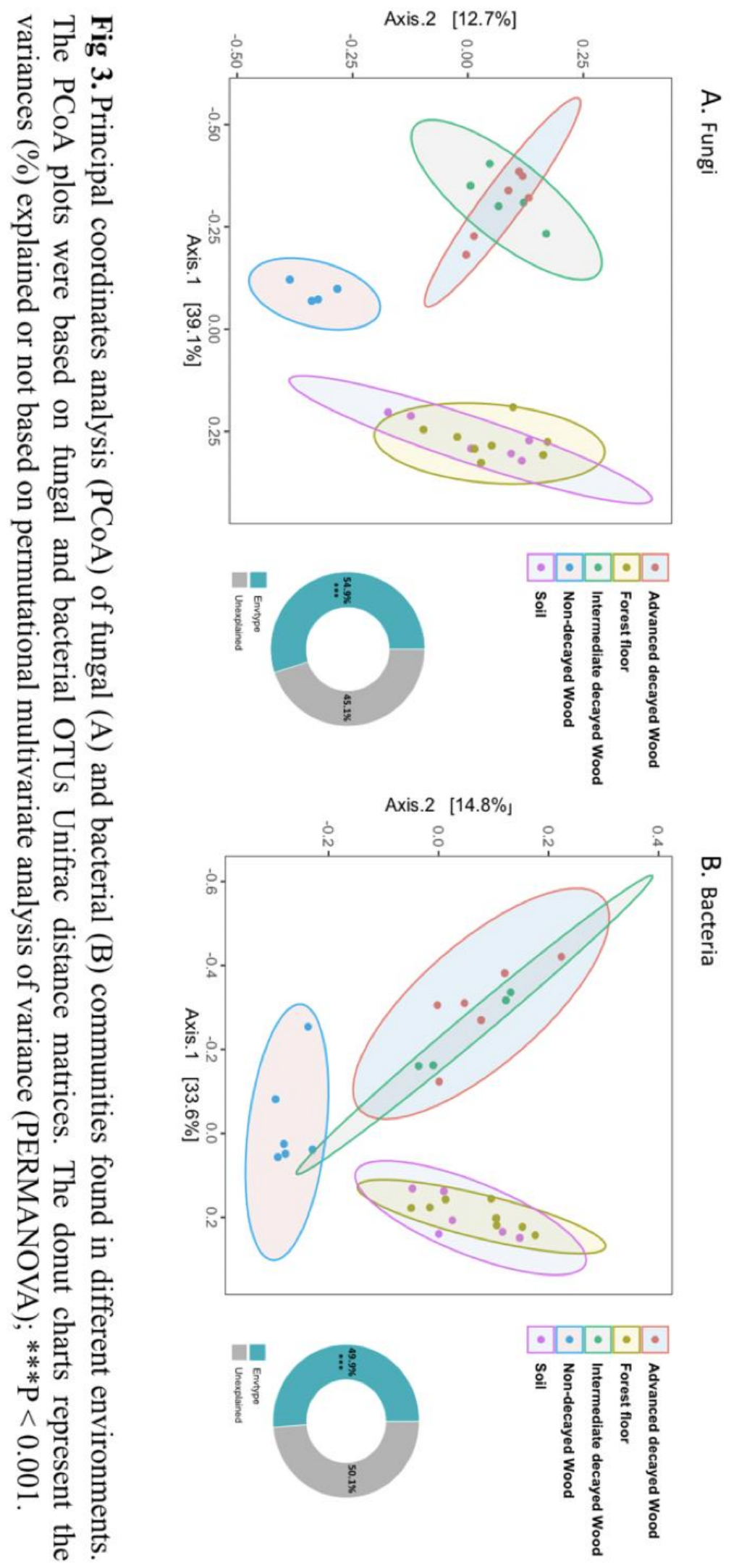



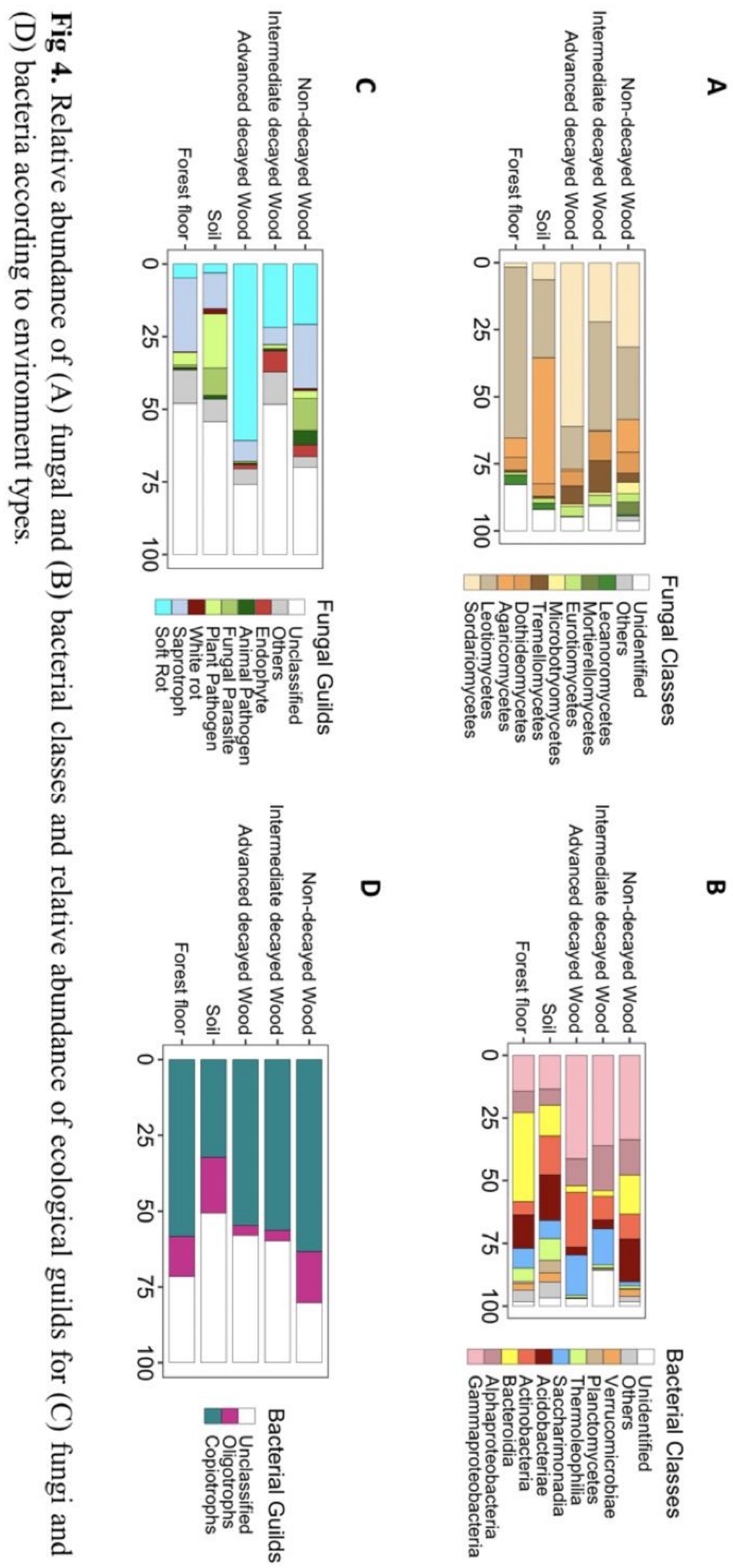


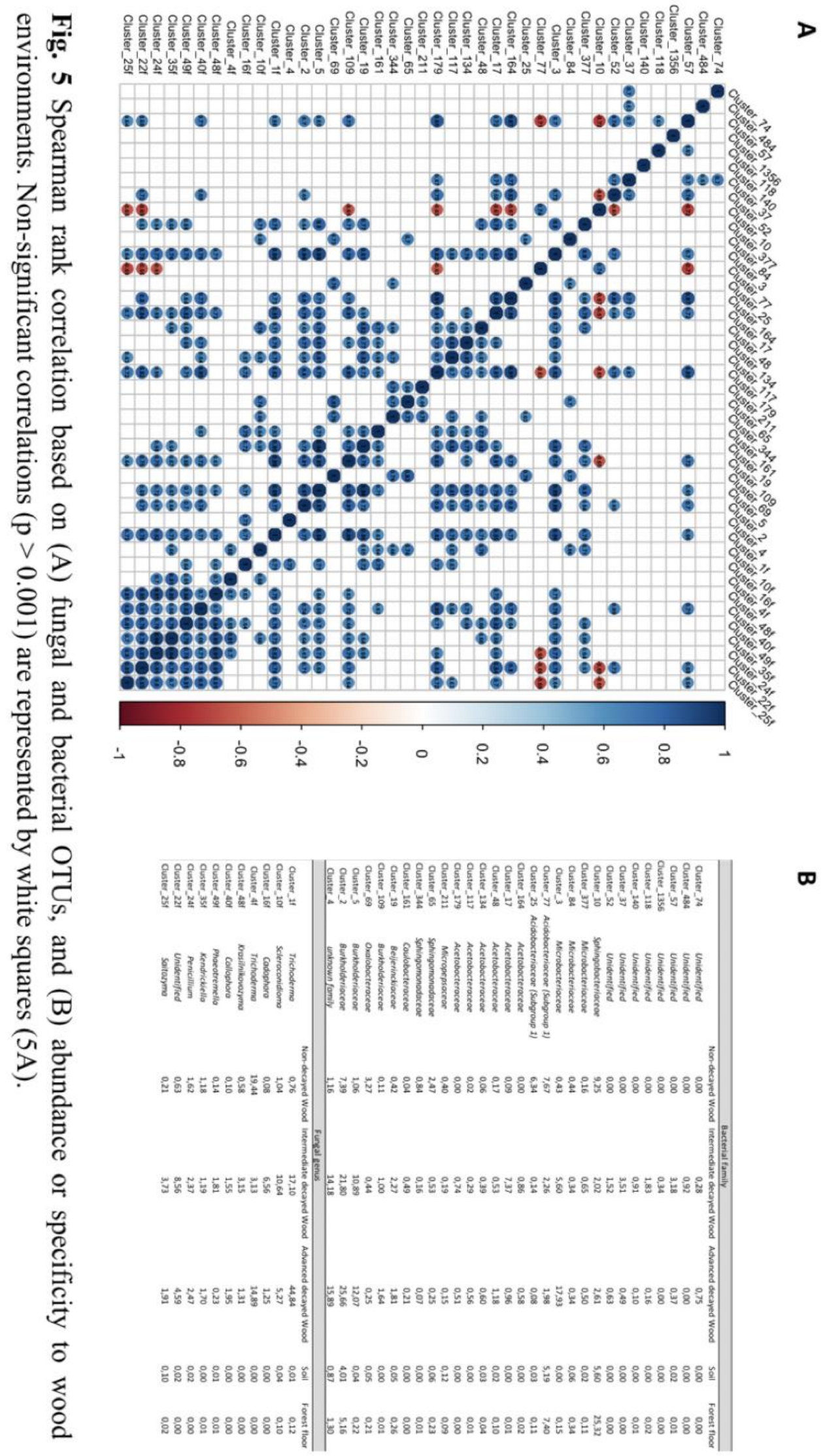

